\title{
Postingestive factors in the control of glucose intake by satiated rats*
}

\author{
NANCY J. KENNEY† \\ University of Virginia, Charlottesville, Virginia 22901
}

\begin{abstract}
Intake of satiated animals, trained to ingest a nutritive solution according to the schedule suggested by Ernits and Corbit (1973) is responsive to postingestive factors. In most animals, oral glucose intake is reduced during gastric or duodenal intubation with nonnutritive Ringer's solution or with a nutritive glucose solution. Therefore, although the hedonic properties of the solution offered are most likely responsible for the initiation of such drinking, postingestive factors are involved in its termination.
\end{abstract}

Ernits and Corbit (1973) have reported that intake of various solutions (preference-aversion functions) by rats which are virtually nondeprived of either food or water are comparable in shape and magnitude to those of water-deprived animals. Under the schedule used by these investigators, rats are allowed free access to food and water except for a 1-h food-deprivation period immediately before the solutions are presented. The deprivation period occurs at a time during the light portion of the light-dark sequence when ad lib food intake is minimal. Water is available during the deprivation period so that the rats may satisfy any postprandial thirst which may have been incurred. Under such a regimen, rats which are neither hungry nor thirsty drink copious amounts of sweet solutions when they are offered.

Ernits and Corbit propose that such intake depends totally on the hedonic properties of the solution offered, i.e., it is completely under oral control. While sole dependence on oral control for initiation of intake is highly probable, postingestive factors may well be involved in the termination of intake, especially intake of nutritive sugars. When rats are offered solutions under the Ernits and Corbit schedule, an inverted-U-shaped function relating intake to concentration is obtained with both saccharin and glucose solutions. The decrease in saccharin intake at high concentrations is most likely attributable to the bitter aftertaste of the more concentrated solutions. Thus, it may very well be under gustatory control. In the case of glucose, however, there is no bitter aftertaste, even at extremely high concentrations. The decrease in intake of glucose solutions with concentrations above the isotonic level is directly attributable to their postingestive effects (Jacobs, 1961, 1962; McCleary, 1953). In the absence of these postingestive factors, intake of glucose is a

*This article is based on a doctoral dissertation submitted to the Graduate Faculty of the University of Virginia. The author wishes to thank Douglas G. Mook and John F. Hahn for their comments on a preliminary version of the manuscript. This research was supported by PHS Grant MH 10766.

tRequests for reprints should be sent to Nancy J. Kenney, Department of Biology, University of Pennsylvania, Philadelphia, Pennsylvania 19174. monotonically increasing function of concentration (Mook, 1963).

If oral intake of a nutritive solution by a nondeprived rat is under the control of postingestive factors, it should be depressed by direct gastric and duodenal stimulation. I will show that, in fact, oral intake of a nutritive solution by animals trained on the Ernits and Corbit schedule is responsive to postingestive satiety cues.

\section{METHOD}

Seven Sherman female rats, weighing between 220 and $270 \mathrm{~g}$, were fitted with gastric and duodenal cannulae under sodium pentobarbitol anesthesia $(45 \mathrm{mg} / \mathrm{kg})$. Cannulae consisted of 13-ga stainless steel hypodermic needles with Luer hubs. Needles were cut to a length of approximately $1 / 2$ in., slid through a piece of polypropylene mesh, and sleeved with a piece of polyethylene tubing (PE 280, Clay-Adams) which was heat-flanged on both ends. Epoxy was used to secure the PE tubing to the needle and to secure a small piece of nylon mesh to the PE tubing midway between the two flanged edges.

The gastric cannula was inserted into the cardiac portion of the stomach through a small slash wound and secured by means of three purse-string sutures. The duodenal cannula was inserted through another small slash wound approximately $5 \mathrm{~mm}$ distal to the pyloric sphincter and secured with two purse-string sutures. The nylon mesh was inserted beneath the muscle wall over the slash wound, while the polypropylene mesh was placed between the sutured muscle wall and skin for support. The Luer hubs of the cannulae were exteriorized on the dorsal-lateral surface just posterior to the rib cage. Cannulae were capped with male tubing-to-needle connectors filled with dental cement.

Immediately following surgery, and every day during the 1 -week recovery period which followed, all animals received prophylactic doses of penicillin $(74,250 \mathrm{units} / \mathrm{rat} /$ day $)$.

Following the recovery period, the rats were trained to drink a $4.5 \%$ glucose solution (W/V, anhydrous dextrose in distilled water) under the Ernits and Corbit schedule. Following a 1-h food-deprivation period in their home cages, rats were placed in tall holding cages consisting of a stainless steel cage with a mesh floor and front. The cage was fitted with a $1-\mathrm{ft}$ wooden extension to increase its height to $18 \mathrm{in.}$ After a 1-h drinking session in the holding cages, intakes were measured to the nearest milliliter, and the animals returned to their home cages. Food was then replaced until the next day. Water was available at all times except during the test hour. One animal refused to drink and another developed a severe respiratory infection. Therefore, only data from the remaining five animals will be reported. 
Table 1

Average Oral Glucose Intake of Intact Female Rats During Gastric or Duodenal Intubation With Isotonic Glucose or Ringer's Solution

\begin{tabular}{|c|c|c|c|c|c|}
\hline \multirow{2}{*}{$\begin{array}{c}\text { Rat } \\
\text { Number }\end{array}$} & \multirow{2}{*}{$\begin{array}{l}\text { No Intu- } \\
\text { bation }\end{array}$} & \multicolumn{2}{|c|}{$\begin{array}{c}\text { Gastric } \\
\text { Intubation }\end{array}$} & \multicolumn{2}{|c|}{$\begin{array}{l}\text { Duodenal } \\
\text { Intubation }\end{array}$} \\
\hline & & Glucose & Ringer's & Glucose & Ringer's \\
\hline 22 & 13.0 & 9.0 & 12.5 & 7.0 & 9.5 \\
\hline 53 & 9.5 & 6.0 & 9.5 & 6.0 & 7.5 \\
\hline 54 & 14.5 & 10.0 & 13.5 & 12.0 & 14.5 \\
\hline 55 & 29.2 & 17.0 & 19.5 & 17.5 & 20.5 \\
\hline 62 & 11.0 & 8.5 & 11.0 & 11.5 & 11.0 \\
\hline $\begin{array}{l}\text { Group } \\
\text { Mean }\end{array}$ & 15.4 & 10.1 & 13.2 & 10.8 & 12.6 \\
\hline
\end{tabular}

Once the animals were drinking reliably, adaptation to the intubing apparatus and to the E's presence in the room during the drinking session was begun. The intubing apparatus consisted of a male Luer connector which could be easily attached to the hub of either the gastric or duodenal cannula. The connector, in turn, was cemented to a length of 13-ga stainless steel tubing about $1 \mathrm{ft}$ long, bent at a right angle about $1 \mathrm{in}$. from the animal. A length of $2 / 16$ o.d. Tygon tubing was press-fit over the distal end of the metal tubing, draped over the top of the cage so that it was inaccessible to the animal, and attached to a 60 -cc syringe. The intubing apparatus was attached to the gastric or duodenal cannula on alternate days until the animal became accustomed to the apparatus and glucose intake had stabilized. Testing then commenced,

Testing consisted of intubing $4.5 \%$ glucose or Ringer's solution through either the gastric or duodenal cannula while the animal was drinking $4.5 \%$ glucose. In the case of gastric intubing, $1 \mathrm{ml}$ of the intubing solution was infused for each milliliter of glucose the animal ingested orally. For duodenal intubing, $1 \mathrm{ml}$ was infused for every $2 \mathrm{ml}$ orally ingested.

Each animal received two blocks of 4 days of intubation. Each intubation series consisted of 1 day of gastric intubation with glucose, one of duodenal glucose, one of gastric Ringer's solution, and one of duodenal Ringer's solution. Order of intubation site and solution within each block was counterbalanced, and the $\mathrm{E}$ did not know which solution was being intubed on any given day. Before and after each intubation series, there was a control day on which the apparatus was connected to one of the cannulae but nothing was infused.

\section{RESULTS AND DISCUSSION}

Nondeprived animals, trained to ingest a nearly isotonic glucose solution, are responsive to cues from caloric materials in the stomach and duodenum (Table 1). Gastric intubation with $4.5 \%$ glucose resulted in a decrease in oral intake compared to intake on control days for all animals $(t=3.108, d f=4$, $\left.\mathrm{p}<.025^{\mathbf{1}}\right)$. Although one animal failed to reduce its oral intake during duodenal intubation with glucose, the average intake of all animals was significantly lower on days on which glucose was intubed intraduodenally than on control days $(\mathrm{t}=2.283, \mathrm{df}=4, \mathrm{p}<.05)$. The animal that did not decrease its intake during duodenal intubation with glucose also showed no decrease in intake during duodenal intubation with Ringer's solution. Another animal did not decrease intake during gastric intubation with Ringer's solution. But in every case, except one in which intakes were nearly equal, gastric or duodenal intubation with glucose resulted in a lower oral intake than did similar infusion with Ringer's solution $(\mathrm{p}<.0005$ for gastric intubation and $\mathrm{p}<.025$ for duodenal intubation). Thus, animals offered a nutritive solution according to the procedures suggested by Ernits and Corbit (1973) are not merely responding to oral cues which regulate intake. In some animals, the presence of bulk in the stomach or duodenum is sufficient to reduce intake. In all instances, such animals are responsive to the presence of caloric material in the gastrointestinal tract.

Therefore, whereas oral factors may initiate such drinking (since it occurs at a time when intake of water and of standard food is minimal), the amount drunk remains sensitive to at least some of the postingestive factors which enter into the control of normal food intake (Kenney, 1974).

\section{REFERENCES}

Ernits, T., \& Corbit, J. D. Taste as a dipsogenic stimulus. Journal of Comparative \& Physiological Psychology, 1973, 83, 27-31. Jacobs, H. L. The osmotic postingestion factor in the regulation of glucose appetite. In M. R. Kare and B. P. Halpern (Eds.), Physiological and behavioral aspects of taste. Chicago: Inniversity of Chicago Press, 1961. Pp. 16-27.

Jacobs, H. L. Some physical, metabolic, and sensory components of appetite for glucose. American Journal of Physiology, 1962, 203, 1043-1054.

Kenney, N. J. The effects of ovariectomy and estradiol replacement on the oral and postingestive controls of short-term food intake. Unpublished doctoral dissertation, University of Virginia, 1974.

McCleary, R. A. Taste and post-ingestion factors in specific-hunger behavior. Journal of Comparative \& Physiological Psychology, 1953, 46, 411-421.

Mook, D. G. Oral and postingestional determinants of the intake of various solutions in rats with esophageal fistulas. Journal of Comparative \& Physiological Psychology, 1963, 56, 645-659.

\section{NOTE}

1. All $p$ values reported are for one-tailed tests.

(R eceived for publication June 25, 1974; accepted July 11, 1974.) 